\title{
A paisagem cultural da cidade de Macapá: o rio comanda a vida.
}

The cultural landscape of the city of Macapá: the river commands life.

El paisaje cultural de la ciudad de Macapá: el río comanda la vida.

José Alberto Tostes

Professor Doutor e Associado III, Unifap, Brasil.

tostes.j@hotmail.com

Antônio da Justa Feijão

Mestrando em Desenvolvimento Regional, Unifap, Brasil.

feijãoamazonia@gmail.com

\section{Cássia Ingrid Rosa Moura}

Graduanda de Arquitetura e Urbanismo e bolsista de iniciação cientifica, Unifap, Brasil. ciclano@hotmai.com 


\section{RESUMO}

O objetivo da pesquisa é analisar a relação das águas, rio/cidade e paisagem cultural em Macapá, no contexto da identidade com o patrimônio da Fortaleza de São José de Macapá e das influências do rio Amazonas na organização do espaço urbano da cidade. Para o desenvolvimento do estudo foi adotado o método histórico dialético com estudo qualitativo e elaboração de cartografias, a investigação foi desenvolvida pelo Grupo de Pesquisa Arquitetura e Urbanismo na Amazônia da Universidade Federal do Amapá. A importância do tema abordado reside na compreensão da relação rio/cidade e paisagem cultural como processos de interação que influenciam na organização do espaço urbano na região Amazônica, a exemplo de Macapá. Os resultados evidenciam que a interação entre águas, rio/cidade e paisagem cultural foi e ainda são fatores extremamente relevantes para a morfologia do lugar e por isso a conexão entre tais agentes não podem ser desconsiderados no planejamento de Macapá, bem como na sensibilização das práticas de preservação ambiental.

PALAVRAS-CHAVE: Rio. Fortificações. Paisagem Cultural

\section{ABSTRACT}

The objective of the research is to analyze the relationship between waters, river / city and cultural landscape in Macapá, in the context of the identity of the Fortaleza de São José de Macapá and the influence of the Amazon River in the organization of urban space in the city. For the development of the study was adopted dialectical historical method with qualitative study and elaboration of cartographies, the research was developed by the Research Group Architecture and Urbanism in the Amazon of the Federal University of Amapá. The importance of this theme lies in the understanding of the river / city relationship and cultural landscape as processes of interaction that influence the organization of urban space in the Amazon region, such as Macapá. The results show that the interaction between waters, river / city and cultural landscape was and still are extremely relevant factors for the morphology of the place and for that reason the connection between such agents can not be disregarded in the planning of Macapá, as well as in the sensitization of the practices Preservation.

KEYWORD: River. Fortifications. Cultural Landscape.

\section{RESUMEN}

El objetivo de la investigación és analizar la relación de las aguas, río/ciudad y paisaje cultural en Macapá, en el contexto de la identidad con el patrimonio de la Fortaleza de San José de Macapá y de las influencias del río Amazonas en la organización del espacio urbano de la ciudad. Para el desarrollo del estudio se adoptó el método histórico dialéctico con estudio cualitativo y elaboración de cartografías, la investigación fue desarrollada por el Grupo de Investigación Arquitectura y Urbanismo en la Amazonía de la Universidad Federal de Amapá. La importancia del tema abordado reside en la comprensión de la relación río / ciudad y paisaje cultural como procesos de interacción que influencian en la organización del espacio urbano en la región Amazónica, a ejemplo de Macapá. Los resultados evidencian que la interacción entre aguas, río/ciudad y paisaje cultural ha sido y siguen siendo factores extremadamente relevantes para la morfología del lugar y por eso la conexión entre tales agentes no puede ser desconsiderada en la planificación de Macapá, así como en la sensibilización de las prácticas de preservación ambiental.

PALABRAS-CLAVE: Río. Fortificaciones. Paisaje Cultural. 


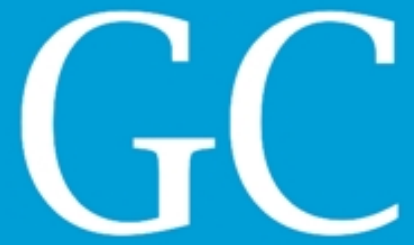

Revista Nacional de Gerenciamento de Cidades

\section{INTRODUÇ̃̃O}

A abordagem a respeito do "O rio comanda a vida" foi embasado na obra de Tocantins (1972) na qual o autor discorre sobre os significados que o rio tem para o homem amazônico, como este age em referência a tais simbologias e como toda essa interação afeta o cotidiano do indivíduo que inconscientemente tem sua vida "comandada pelo rio".

Em se tratando da cidade de Macapá os registros históricos apontam como proposito de sua fundamentação a defesa do território, na qual o rio Amazonas foi percebido como estratégico e por isso a Fortaleza São José de Macapá foi construída na sua margem para impedir a invasão da região por estrangeiros.

Desde sua formação Macapá possui uma forte conexão com o rio marcada tanto na sua estrutura física quanto posteriormente na relação comercial que se desenvolveu com o estado do Pará, pois nesse período simbolicamente o rio Amazonas exercia de forma exclusiva o papel de caminho, por onde circulavam pessoas e mercadorias que na chegada atracava no Trapiche Eliezer Levy conforme pode ser observado na figura 01.

Figura 1 e 2, respectivamente: Trapiche Eliezer Levy e vários barcos atracados; Trapiche Eliezer Levy e a Fortaleza de São José de Macapá. Fotos da orla de Macapá da década de 50.

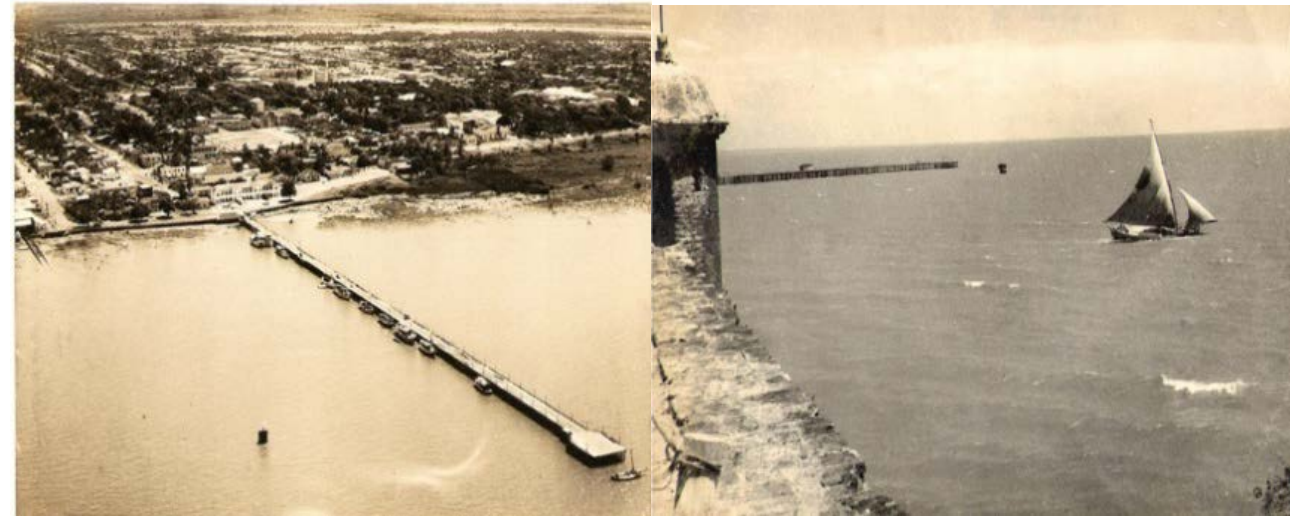

Fonte: HTTP://CASTELOROGER.BLOGSPOT.COM.BR/2011.

Fundamentado na descritiva histórica do processo de organização da cidade de Macapá não se pode negar que a paisagem cultural de Macapá foi delineada a partir do influxo integral que existiu com o rio Amazonas assinalando uma relação simbiótica entre seus habitantes, a cidade e o próprio rio (Figura 1).

Assim, a relevância da pesquisa consiste na compreensão da relação rio/cidade e paisagem cultural como processos de interação que influenciam na organização do espaço urbano na região Amazônica, a exemplo de Macapá, enfatizando o elo existente, entre o homem, natureza e os fatos sociais que desenharam cidades distintas na sua forma, tendo no rio a mais poderosa força que comandou a vida na Amazônia. 
Todo o ordenamento do estudo embasou-se na utilização do método histórico dialético com estudo qualitativo e elaboração de cartografias fundamentadas em imagens histórias utilizandose bases cartográficas de 2014 do Exército Brasileiro (EB) e Secretaria de Meio Ambiente do Amapá (SEMA), todas tratadas por técnicas de georreferenciamento com uso de ferramentas do software Arc Gis 10.1.

A investigação foi desenvolvida pelo Grupo de Pesquisa Arquitetura e Urbanismo na Amazônia da Universidade Federal do Amapá. O suporte conceitual está baseado na discussão sobre a valorização do rio no transcurso do desenvolvimento da paisagem cultural nas cidades amazônicas tomando, por exemplo, Macapá. Os autores que conduziram a fundamentação do estudo foram (Tocantins 1960;1972;2000; Wagley, 1988; Benchimol, 2009; Carrel, 2016; Tostes, 2014; Camilo, 2003;).

Em conclusão, as questões investigativas propostas neste trabalho partem da seguinte premissa: a cidade de Macapá está reconfigurando sua relação com o rio e se fixando como centro difusor e receptor de um novo nexo que põe a economia no ponto central do seu eixo de desenvolvimento, aspecto que vem causando uma modificação acelerada na sua paisagem cultural e na sua relação com o rio.

\section{O CONTEXTO ENTRE O RIO E A CIDADE}

Os acontecimentos que envolvem a vida do homem na Amazônia sempre estiveram condicionados a interpretação da realidade na qual este se insere. $O$ ambiente natural na perspectiva do domínio das águas sobre o comando da vida é real no quadro de evolução das populações amazônicas. A respeito disso Tocantins descreve que:

[...] os rios são a fonte perene do progresso, pois sem ele o vale se estiolaria no vazio inexpressivo dos desertos. Esses oásis fabulosos tornaram possível a conquista da terra e asseguraram a presença humana, embelezaram a paisagem, fazem girar a civilização - comandam a vida no anfiteatro amazônico. (TOCANTINS, 2000, p. 278)

Ainda, sobre a vida Amazônica Tocantins (1960) narra que os indígenas eram dotados de um saber minucioso a respeito da dinâmica do rio, obviamente esse era um conhecimento tradicional carregado de simbologias, misticismo e credos na natureza como um organismo vivo que possuía espirito, em outras palavras o rio ensinou aos indígenas e esses passaram aos triétnicos que há uma equação de territórios demográficos marcado pela capacidade do rio em prover os insumos naturais bióticos e florestais. Benchimol ratifica a contribuição do conhecimento indígena no processo de ocupação do território amazônico ao dissertar que:

A contribuição indígeno-cabocla para ocupação e desenvolvimento da Amazônia foi, no entanto, considerável e sem ela a tarefa de descoberta e exploração teria sido 
Para Carrel (2016) mesmo não conhecendo essa simbiose natural entre rio e sociedade triétnica o meio põe no homem a sua marca. Ideia que se aplica bem a essa relação ancestral com os indígenas e a nova sociedade triétnica dessas vilas, cidades, todas "hidro urbis", que revelam como realmente o rio foi comandando a vida que vassalou não a economia do lugar, mas, e principalmente, a ordem urbana dessas cidades amazônicas.

Nesse sentido, a civilização contemporânea ampliou seu conhecimento a respeito do rio e passou a utilizar sua capacidade em benefício próprio. Com o crescimento acelerado da população e sua concentração na cidade o rio passa a ser principal fonte de geração de energia elétrica através do aproveitamento do fluxo das águas, também é a principal fonte de captação de água para o atendimento das necessidades urbanas e infelizmente em alguns casos serve de deposito pera o descarte de resíduos gerados pelo homem.

O rio continua sendo provedor de insumos mais agora sob a lógica do capital que molda a cidade e o ambiente natural aos seus interesses e com isso tenta inverter a relação do rio que dominava para o rio que é dominado. Logo, a relação rio-cidade, se difunde como um aspecto crucial para o desenvolvimento urbano.

Nesse enquadramento a fortaleza de São José de Macapá pode ser lida como o primeiro encontro urbano harmonioso entre o rio e cidade. Tostes (2014) destaca a fortaleza como o elemento principal, talvez único, que demarca a paisagem de Macapá nos seus 248 anos de criação. "Sem a Fortaleza não seria possível estabelecer um elo mais intenso entre o passado e o presente" (Tostes, 2014, p.28), enfoque que será elucidado no sub tópico a seguir.

\subsection{A FORTALEZA DE SÃO JOSÉ CELEBRA A RELAÇÃO DE MACAPÁ COM O RIO}

Camilo (2003) revela que alguns especialistas em História urbana observam que nem sempre as fortificações foram construídas em face de um perigo iminente, mas acabaram por se tornar elementos integrantes do processo de urbanização do Brasil, pois compunham o conjunto de formas arquitetônicas que transformaram a paisagem no período colonial.

Inserida nesse contexto de urbanização estaria a Fortaleza de São José de Macapá, que foi erigida para assegurar o domínio luso no extremo norte da colônia e, também, prevenir o lugar de um ataque inesperado ao mesmo tempo em que serviria de incentivo para a ocupação da região. A cidade de Macapá de certa forma tornou-se testemunha ocular da falência dos propósitos pombalinos em fazer da Fortaleza de São José a semente fertilizadora de uma grande cidade às margens do rio Amazonas.

Ao contrário a Fortaleza de São José de Macapá produziu uma réstia urbana muito discreta. Esse encapsulamento da dinâmica natural dos centros difusores de colonização (fortalezas e portos) de início não produziu os efeitos desejados em Macapá. Porém, não se pode condenar sozinho 
Revista Nacional de Gerenciamento de Cidades

o rio por esse fracasso, em partes isso se deve também a formação do solo do tipo latossolos gleizados que são muito pobres para a agricultura somados às doenças emergentes em hidro cidades e as áreas úmidas (Ressacas ${ }^{1}$ ) que desestimulou a permanência de muitas pessoas na Região.

Efetivamente a força e importância do rio sobre a vida da sociedade triétnica, suas economias locais e regionais é de tamanha dependência com o rio Amazonas que os indivíduos amazônicos passaram construir suas hidro cidades a partir de uma dinâmica política, cultural e econômica que era viabilizada na integração do rio como eixo principal do processo de desenvolvimento urbano como é o caso de Macapá retratado na figura 03.

Figura 3: Cartografia elaborada sobre ortofotos destacando os elementos paisagísticos culturais e de produção da cidade/rio.

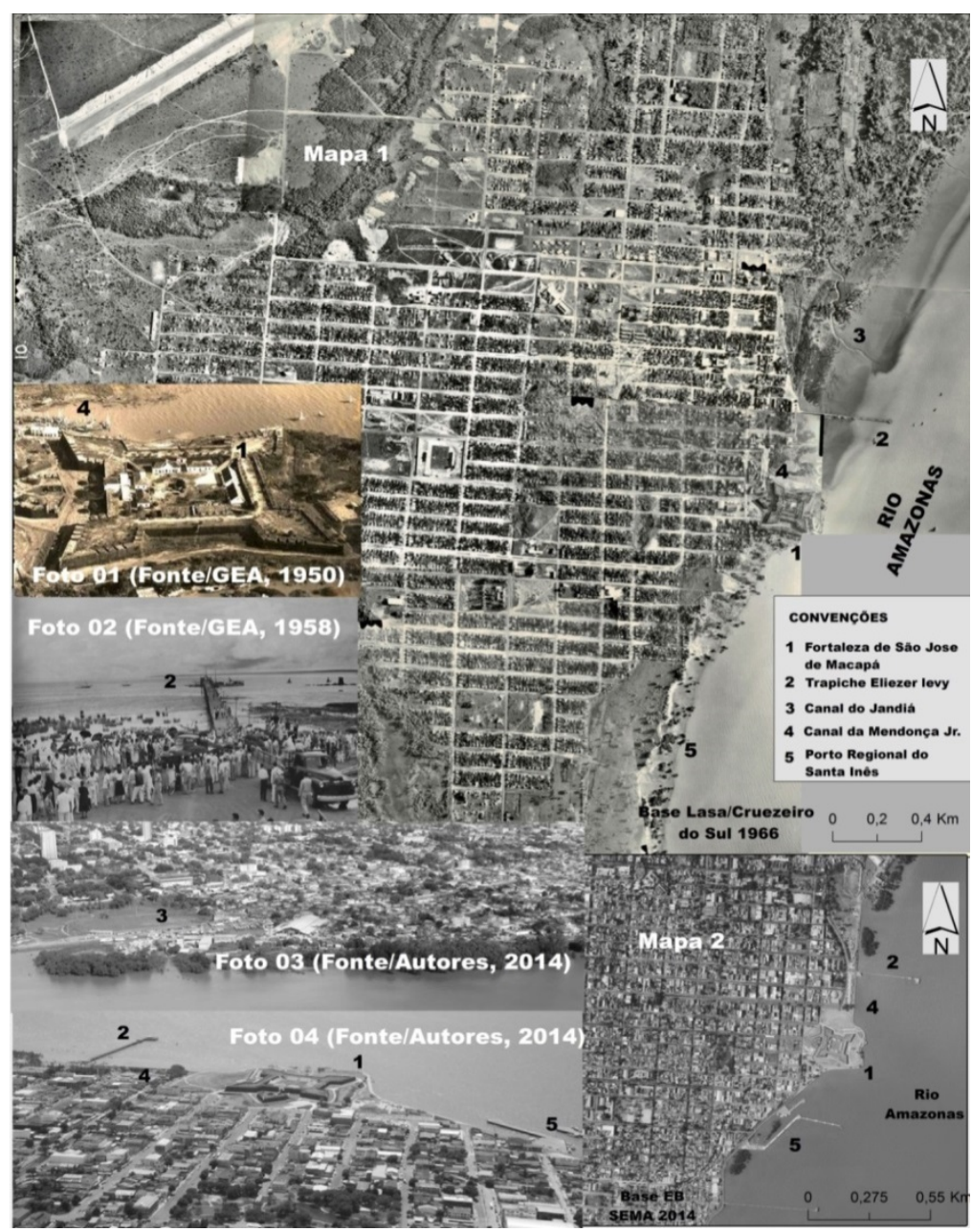

Fonte: ACERVO DA ICOMI - IMAGENS LASA, 1966. CRÉDITO ELABORAÇÃO: TOSTES \& FEIJÃO, 2017.

${ }^{1}$ As ressacas são bacias de recepção configurando como fontes naturais hídricas pertencente à rede de drenagem do Amazonas. (Definição utilizada pela Secretaria Estadual do Meio Ambiente do Amapá - SEMA). 
Na cartografia nota-se que todo o processo de ordenamento do espaço ocorreu em função e a margem do rio tendo a fortaleza como ponto inicial da evolução urbana que posteriormente se irradiou para outras áreas. Portanto, entendemos que a conexão da Fortaleza São José de Macapá com rio Amazonas e a cidade de Macapá nuca foi estática e jamais serão estáveis diante do enredo de ações que embalam esses três atores.

À vista disso, acentua-se a existência de uma ligação vital entre esses atores a ser considerado no processo de desenvolvimento urbano que respeite a cultura e as peculiaridades locais. No viés histórico por meio da proteção do patrimônio histórico cultural; na sustentabilidade ambiental com a conservação do ecossistema natural e no urbano pautado na gestão democrática da cidade. Assim será viável o planejamento de uma cidade que não desconstrói sua relação com o rio e com sua história, mas sim a enrique enquanto busca o progresso.

\section{ANÁLISE DO RIO QUE COMANDA A VIDA NA CIDADE DE MACAPÁ 1990 A 2016}

Tostes (2014) destaca que a compreensão histórica da evolução da cidade de Macapá é primordial se proceder à intervenção arquitetônica nessa relação histórica e cultural entre a cidade e o rio que se marca por uma energia forte e permanente entre ambos. Sob a ótica da transformação do ambiente para melhoria das condições sociais Wagley cita que:

A terra só é útil ao homem na medida em que ele possui o equipamento cultural, em um determinado lugar ou ocasião, e na medida em que ele sabe utilizar. (...) Todos os povos têm a mesma potencialidade para melhorar a condição social; o ambiente físico em que vivem é apenas um dos muitos fatores que determinam o complexo ajustamento do homem à sua ambiência. (Wagley, 1988, p. 39)

Macapá representa um exemplo de evolução de cidade que no início do século XVIII, tinha uma população que sofria com as mazelas intrínsecas às áreas úmidas e com o advento das tecnologias da engenharia, reconquistou sua dinâmica de crescimento ampliando as relações comerciais regionais e locais reconquistando a importância do rio para a cidade e vida da sociedade triétnica dessa região.

No auge do ciclo da borracha, precisamente em 1790, quando houve um censo da população de Macapá, a população registrada nesse censo foi da ordem de 2.532 habitantes. Fato destacável é que mesmo no período da extração da borracha Macapá vive um apagão demográfico, quando houve um incremento de apenas 18 habitantes num período de 29 anos. De 1820 a 1940, ou seja, passados 120 anos, a população de Macapá somente chegou a um total de 10.601 habitantes e um crescimento anual de 67 habitantes anos como mostra o gráfico 01 . 


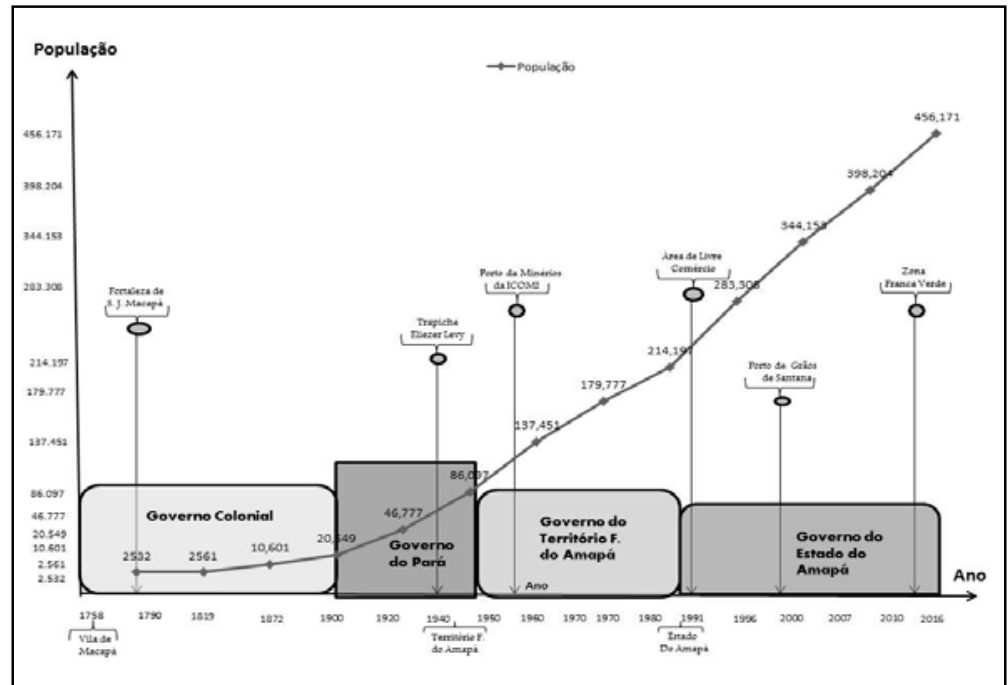

Fonte: PESQUISAS DO INSTITUTO BRASILEIRO DE GEOGRAFIA E ESTATÍSTICA (IBGE). CRÉDITO ELABORAÇÃO: TOSTES \& FEIJÃO, 2017.

No Delta do Amazonas, depois da criação do Território Federal do Amapá (TFA) e instalação do Estado, a sociedade triétnica soube potencializar os conhecimentos que as sociedades imemoriais amealharam durante milênios. A criação do Território do Amapá deslocou o comando político do Estado do Pará para a cidade de Macapá. Assim, de uma arquitetura e marcas urbanas palimpsestas, a cidade passa a "governar" sua própria relação cultural e urbana com o rio.

As transformações insculpidas na orla de Macapá decorrem da mudança de gestão política administrativa do Estado do Pará para a "sub autonomia" do Território Federal do Amapá (Morais \& Rosário, 2009). Com a criação do TFA em 1943 e a consequente transferência da capital do novo ente federativo para Macapá, começa uma nova ordem de colonização entre rio-cidade, dessa vez no sentido inverso: da terra para o rio.

A força dos agentes transformadores nas relações rio-cidade-sociedade evoluíram de um contexto local geopolítico a partir da construção da Fortaleza São José de Macapá, criação do TFA em 1943 e transformação deste em Estado em 1988 até a instalação da Área de Livre Comércio de Macapá e Santana em 1991 e Implantação da Zona Franca Verde e Complexo Agrologístico do Porto de Santana, em 2016. Então, depreende-se que mudanças mais profundas estão por vir.

O fortalecimento econômico do Estado Amapá eleva a importância econômica e logística de Macapá como cidade polo de desenvolvimento atraindo as economias das cidades paraenses no Arquipélago de Marajó e sua juventude para consumir seus serviços culturais, serviços de laser e ensino acadêmico, a nova dimensão das relações urbanística e portuárias, apropriando- 


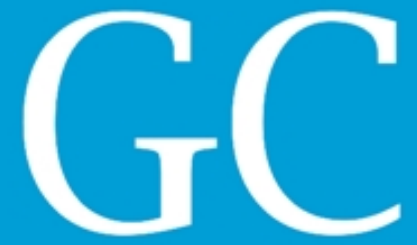

Revista Nacional de

se mais do rio e exigindo de seus habitantes um empoderamento do rio nessa nova plataforma cultural e paisagística rio-cidade como mostra a figura 04 .

Figura 4: Cartografia da distribuição espacial das localidades ribeirinhas concêntricas à Macapá no Delta do Amazonas.

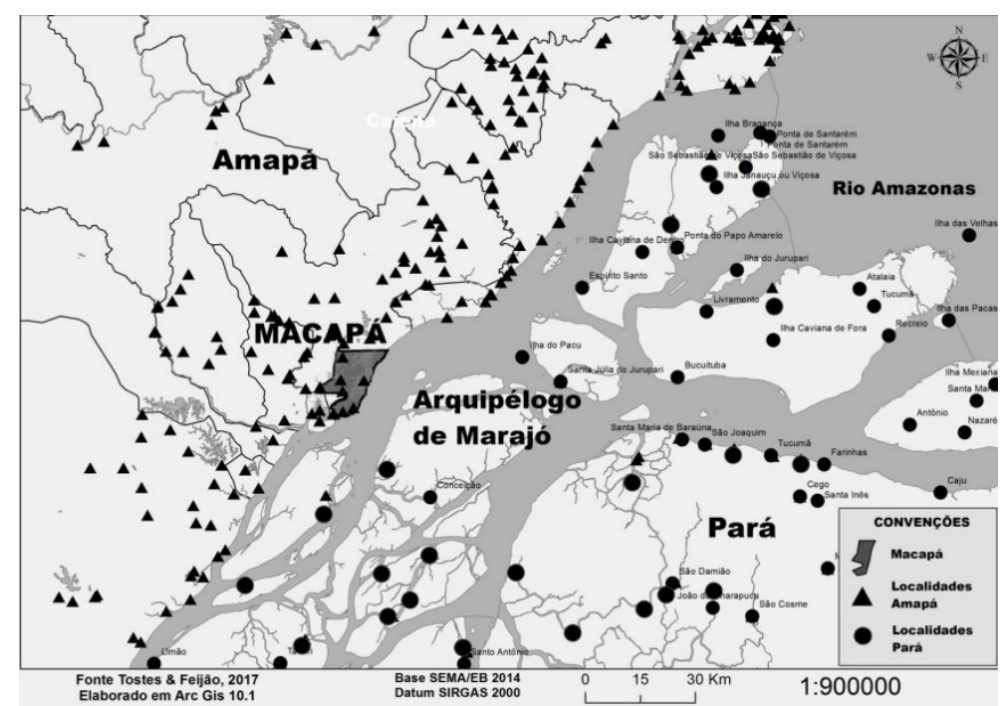

Fonte: BASE SEMA/EB, 2014. CRÉDITOS ELABORAÇÃO: TOSTES \& FEIJÃO, 2017.

Em se tratando do desenvolvimento urbano de Macapá a cidade começa a exercer maior atratividade e obtendo certa centralidade sobre as demais localidades identificadas na figura 04. Devido a sua localização geográfica estratégica e pelo fato de estar de frente com as vilas e cidades do Delta do Amazonas a capital do Amapá tece uma teia de conexões com esses territórios do Pará colocando o rio Amazonas mais uma vez como personagem principal nessa nova sinergia de organização sociocultural e espacial.

\section{AS PRÁTICAS AMBIENTAIS, A PRESERVAÇÃO E A SENSIBILIZAÇÃO PARA O USO DO RIO}

Sobre a temática de práticas ambientais, preservação e sensibilização para o uso do rio devemos levar em consideração que especificamente na Amazônia o rio é ligado à vida, seja por estar ligado a questão de sobrevivência, a questão de territorialidade, ligado ás questões econômicas, ligado inclusive ás relações que são estabelecidas no rio entre os diferentes cantos do mundo. Tostes (2015) cita que o rio, na região amazônica ainda é pouco analisado quando relacionado as funções da cidade, mesmo já existindo um bom número de estudos a respeito do rio em caráter social e antropológico.

Em Macapá não poderia ser diferente, o fato de o Rio Amazonas está situado em todo o perímetro da orla da cidade acabou criando uma hidrovia que faz vários tipos de conexão rio/cidade, exercendo diversos tipos de atividades. Podemos destacar que dentre todas essas 
conexões, uma das mais evidentes são as conexões com as ilhas do Pará, que mesmo sendo de outro estado, as pessoas que ali residem/residiram viram em Macapá uma perspectiva de melhoria de vida, e aqui vieram morar ou viram a cidade como um ponto de comercialização de produtos.

Todavia, é notório que não há uma preocupação especifica com as questões que envolvam a preservação do rio pelo elevado teor de concentração de resíduos sólidos, lixos urbanos às margens, esgoto despejado e inclusive restos de produtos comercializados no decorrer da orla são encontrados. Analisando o perímetro urbano da orla da cidade, atualmente existem dois lugares que exercem papel comercial nesse trecho, são esses o lgarapé das mulheres no Bairro Perpetuo Socorro e a "rampa" do Bairro Santa Inês, essas duas áreas acabam contribuindo com impactos significativos dentro de uma esfera de olhar a condição da vida como um fator crucial. Não verifica-se dentro das perspectivas de natureza de desenvolvimento econômico que envolvem tais circunstancias que haja uma preocupação de caráter de natureza histórica e social com o processo de sensibilização natural das populações envolvidas numa faixa de domínio de pelo mínimo 500 metros a partir da margem do Rio Amazonas.

Além da problemática da orla da cidade, em Macapá podemos observar uma clara demanda da necessidade de sensibilização e de preservação nas áreas que aqui intitulamos de Ressacas, que são ocupações irregulares em áreas úmidas de proteção ambiental e foram geradas a partir das migrações dos moradores oriundos das ilhas do Pará e do interior do próprio Estado do Amapá. Moura e Moreira (2002) apud Tostes e Ferreira (2016) explicam que o processo de urbanização das cidades amazônicas ocorreu de forma acelerada e desordenada, fato que gerou degradação em áreas ambientais com a ocupação em áreas de risco ou de preservação obrigatória, refletindo claramente na insustentabilidade urbana. Durante o processo de ocupação nas áreas de ressacas é retirada a vegetação do local acompanhado de aterramento, despejo de lixo doméstico, tanto dos moradores das ressacas como dos habitantes da área de entorno, também têm os dejetos humanos que são lançados diretamente sem nenhum tipo de tratamento poluindo as águas, além de provocar mudanças no ecossistema e transformando a configuração paisagista do entorno das ressacas. Dentro desta relação homem - natureza que vai transformando as áreas de ressacas, podemos observar um outro problema muito sério, que é provocado pelo aterramento das ressacas, o que provoca a obstrução dos canais naturais que se ligam ao rio Amazonas, causando assim, a ruptura do ciclo biológico de reprodução da fauna e flora, para os quais as áreas de ressacas são de fundamental importância.

Muito embora todas as circunstâncias relativas a somatória dos grandes eventos que decorrem para o desenvolvimento da economia da cidade de Macapá, numa escala que vai desde o período dos anos 1990 até 2017, verifica-se que ainda é necessário se observar em relação ao rio e ás áreas úmidas às práticas de sustentabilidade. No ano de 2004, com o advento do Plano Diretor Participativo de Macapá, houve a promulgação de várias leis sobre as questões ambientais da cidade, tombando como patrimônio ambiental da cidade toda e qualquer área

\footnotetext{
2 Ponto de atracadouros de embarcações fluviais, conhecido regionalmente como "rampa".
} 


\section{Revista Nacional de}

úmida e estabelecendo estratégias de desenvolvimento, de estruturação e de instrumentos indutores para o município em relação as ressacas, o perímetro da orla e afins. Mas mesmo depois de treze anos de publicação desta lei, vários são os conflitos que existem para a aplicação das mesmas em todas as esferas, onde os prejudicados são únicos e exclusivamente o homem e a natureza.

A paisagem da cidade de Macapá sempre foi conectada com o rio e o sentimento de pertencimento que os habitantes têm é muito grande, quando se fala na cidade de Macapá, pensa-se logo no rio Amazonas. Essa relação é gigantesca que envolve desde o desenvolvimento da economia até a relação humana. A composição dos elementos da paisagem exige que para ocorrer a preservação do rio torna-se necessário a mitigação de impactos urbanos e ambientais.

Quadro 1: Principais ações para mitigar conflitos urbanos.

\section{MITIGAÇÃO DE IMPACTOS SOBRE ÁS AGUAS NA CIDADE DE MACAPÁ}

1 - Cada Agente/Ator se limita ao seu papel institucional e ser apenas coadjuvante em casos onde houver necessidades de inter-relação para resolução de determinada problemática de interesse coletivo;

2 - Planejamento urbano de médio e longo prazo com oferta de alternativas compatíveis para a solução dos problemas de curto prazo;

3-O público municipal precisa melhorar se articular para conseguir investimentos junto ao governo Federal e Estadual para implementar nas áreas de infraestrutura urbana;

4 - Desenvolver e executar metodologias participativas para fortalecer o empoderamento social;

5 - Ações de sensibilização quanto ao cuidado com espaço urbano tendo por objetivo a sustentabilidade da cidade para as presentes e futuras gerações e criação do zoneamento Ambiental participativo;

6 - Monitoramento das atividades e serviços realizados na orla do rio;

7 - Fiscalização e controle das pequenas e médias embarcações no manuseio de mercadorias e poluição das águas.

Fonte: TOSTES E FERREIRA, 2016, P.13. ADAPTAÇÃO: TOSTES \& MOURA, 2017.

As ações de mitigação com ação institucional para preservar o corpo hídrico formado pelo rio Amazonas, lagos, igarapés, ressacas, recorte de rio e córregos são fundamentais para a preservação da paisagem urbana. Tostes e Ferreira $(2016$, p. 17) afirmam que entre as medidas idealizadas a partir da construção do empoderamento social e dos documentos oficiais produzidos resultaram em uma série de pontos que norteiam as diretrizes para as chamadas 
áreas úmidas e para orlas de rios a partir da ocupação informal, estruturas precárias, perfis de ocupação, os níveis de aterramento do solo e os danos nas margens dos rios.

a) Educação Ambiental no contexto nas áreas úmidas e controle e poluição das águas;

b) Planos diretores integrados com as políticas públicas e vetores ambientais;

c) Planejamento habitacional compatibilizado com os estudos das áreas úmidas;

d) Cadastro social construído a partir das informações conjugadas das instituições participantes;

e) Instrumentos de orientação sobre a legislação municipal através das Leis existentes (Postura, Solo e Edificações) e a direta relação com as áreas úmidas e controle das águas;

f) Investimentos em infraestrutura urbana e ambiental;

g) Monitoramento sobre a questão latifundiária urbana e ocupação de faixas de rios;

h) Controle e monitoramento do fluxo migratório;

i) Empoderamento social com a formação paritária das diversas instituições;

j) Gerenciamento urbano com os dispositivos tecnológicos;

k) Formação das chamadas faixas verdes no entorno das áreas úmidas e orlas de rios.

\section{CONSIDERAÇÕES FINAIS}

O contexto de interação entre rio Amazonas e cidade de Macapá corresponde a uma escala abrangente que envolve intercâmbios, pontos de passagens e lugares de encontro marcados na história da evolução da cidade. Desse modo, negar a função do rio e toda sua importância para a organização espacial e cultural da cidade chega a ser concretamente uma violação ao direito à cidade.

Ter ciência de que o rio é parte integrante da paisagem urbana é imprescindível para a adoção de ações, planos, programas e políticas públicas que enxerguem na paisagem fluvial do rio o pertencimento deste a cidade, isso não pode ser deixado de lado, tampouco ser menosprezado pelos gestores no planejamento urbano de Macapá.

Assim sendo, teremos na relação com o rio a identidade do cidadão amapaense amazônico fator que diferencia Macapá de muitas cidades brasileiras. Nessa arena, cidade, rio e sociedade não são seres distintos, mas um só elemento - vida. Ao final chega-se a estação de partida. Uma verdade inconteste que, na Amazônia, em pleno século XXI, a frase de Leandro Tocantins ainda reina, pois, o "Rio Comanda a Vida" faz todo sentido para os habitantes da cidade de Macapá. Preservar e sensibilizar para importância dos corpos hídricos passam essencialmente por entender que o contexto econômico não pode ser isolado de um contexto de valorização das águas, e principalmente do uso. Contribui para valorizar o espaço e o significado da paisagem cênica do lugar. As ações de sensibilização previstas nos instrumentos públicos já existentes como o Plano Diretor e as leis complementares podem garantir os índices de manutenção e preservação de qualidade de vida urbana em relação ao uso das águas. 


\section{REFERÊNCIAS BIBLIOGRÁFICAS}

BENCHIMOL, S. Amazônia - Formação social e cultural. 3ạ ed. Manaus: Editora Valer, 2009.

CAMILO, J. V. Homens e pedras no desenho das fronteiras: a construção da Fortaleza de São José de Macapá (1764/1782). Dissertação de Mestrado em História Social, Universidade de Campinas, São Paulo, São Paulo, Brasil: UNICAMP, 2003.

CARREL, A. O Homem, esse desconhecido. São Paulo: Editora Edipro, 2016.

DIAS, P. M., \& Rosário, I. S. Amapá: de Capitania a Território. 2ª̣ ed. Macapá: Editora JM Gráfica, 2009.

TOCANTINS, L. O rio comanda a vida. 4a ed. Rio de Janeiro: Companhia Editora Americana, 1972.

TOCANTINS, L. O rio Comanda a vida: uma interpretação da Amazônia. 9ạ ed.Manaus: Editora Valer/Edições do Governo do Estado, 2000.

TOCANTIS, L. Amazônia: natureza, homem e tempo. Rio de Janeiro: Editora Gráfica Borsoi Ltda, 1960.

TOSTES, J. A. Do tijolo nu ao concreto bruto. Macapá: Autor, 2014.

TOSTES, J.A. Pensar a cidade. João Pessoa: Sal da Terra, 2014.

TOSTES, J. A., DIAS, S. F. As fragilidades urbanas e ambientais de áreas de ressaca na Amazônia. (In) Compatibilidade entre áreas de proteção ambiental e assentamentos precários: como andam as intervenções nas cidades brasileiras. IV enanparq - Encontro da Associação Nacional e Pesquisa e Pós-Graduação em Arquitetura e Urbanismo. Porto Alegre, 2016.

WAGLEY, C. (1988). Uma Comunidade Amazônica. 3ạ ed. São Paulo: Editora da Universidade de São Paulo. 